\title{
Mixed Layer Depth in the Aegean, Marmara, Black and Azov Seas: Part I: General Features
}

\author{
A. Birol Kara *, Robert W. Helber, \\ Oceanography Division, Naval Research Laboratory, Stennis Space Center, MS, \\ $U S A$ \\ Timothy P. Boyer, \\ NOAA National Oceanographic Data Center, Silver Spring, MD, USA \\ James B. Elsner \\ Department of Geography, Florida State University, Tallahassee, FL, USA
}

\begin{abstract}
Climatological fields of mixed layer depth (MLD) are presented over the Aegean, Marmara, Black and Azov Seas. Monthly fields of MLD are formed by historical individual temperature and salinity profiles from combination of various data sets with additional quality control procedures applied. Various definitions that are based solely on temperature $(T)$ or those that include the impact of salinity $(S)$ are applied to investigate the robustness in the pattern and values of the MLDs. Interpolation of the MLD fields to a $0.25^{\circ} \times 0.25^{\circ}$ regular grid over the region is accomplished using a combination of median filter and ordinary kriging. Strong seasonal variability is noted in all regions. Given a density-based MLD criterion that includes both $T$ and $S$, deep mixed layers $(>200 \mathrm{~m}$ ) are noted in the Aegean Sea, especially eastern part of the region during winter while MLDs are generally much shallower $(<60 \mathrm{~m})$ in the Black Sea. A criterion based on curvature method, which determines MLD according to first maximum of curvature of $T$ may fail in representing deep MLDs in the Aegean Sea when the water column is well mixed. MLD fields obtained from all definitions are found to be strongly correlated to each other over the seasonal cycle, confirming the strong seasonal cycle. While the curvature method gives shallow MLDs only during winter, it has relatively large skill in comparison to the density-based MLD criterion. In general, MLD fields suffer from lack of input $T$ and $S$ profiles in the Marmara and Azov Seas, thus they may not be representative. Monthly MLD fields presented in this paper are available for various applications, such as mixed layer studies, ocean biology, ocean modeling and acoustic propagation.
\end{abstract}


Key words: Mixed Layer Depth, The Agean and Black Seas, Kriging, Climatology,

\section{Motivation}

There have been various studies examining major features of mixed layer depth (MLD) over the global ocean (e.g., Kara et al., 2003; Lorbacher et al. 2006). There are also some regional studies, including the North Pacific Ocean (Ohno et al., 2003; Suga et al., 2004), the equatorial Pacific Ocean (Lukas and Lindstrom, 1991), the western equatorial Atlantic (Pailler et al., 1999), the South China Sea (Qu et al., 2007; Aijun et al., 2006), Mediterranean Sea (D'Ortenzio et al., 2005) and the Bering Sea (Miura et al., 2002).

Little or almost no attention has been given to characteristics of MLD in the Aegean, Marmara and Black Seas. As part of the Mediterranean Sea, the study by D'Ortenzio et al. (2005) included analysis of MLD in the Aegean Sea, but it did not present spatial and temporal variability in the whole region, in detail. As of this writing, there has been no study which describes seasonal characteristics of MLD in the Aegean, Marmara, Black and Azov Seas, whose bottom topography is quite variable (Figure 1). A lack of the understanding of major features of MLD in these regions has motivated this study. In addition, the knowledge of MLD is particularly important for biological studies in the Black Sea, where the autumn and spring blooms usually take place in the mixed layer (Oguz et al., 2000), and oxygen distribution is of particular importance for biogeochemical processes (Oguz et al., 2001). The Marmara Sea is also of particular importance since the strong density gradient layer between water masses may have quite large influences on mixing processes (Besiktepe et al. 1994).

The major goal is to present spatial and temporal variability of MLD on the climatological time scales for various purposes, such as ocean mixed layer studies, ocean biology, near surface acoustic transmission and model-data validations of MLD from an ocean general circulation model (OGCM). In studying general features of climatological monthly means of MLD, we process historical temperature and salinity profiles from very comprehensive, up to date and quality-controlled data sets, extending up to 2006. MLD is then determined at the locations where individual profiles are located. This is accomplished with various definitions. The reason for applying different MLD definitions based on $T$ only or including the impact of $S$ through density is to examine (1) how robust the results are, (2) how important the effect of salinity is, and (3) what relationship might exist among the MLD fields.

After obtaining the irregularly-spaced MLD fields at individual $T$ and $S$ locations based on various definitions, fine resolution $\left(0.25^{\circ} \times 0.25^{\circ}\right)$ gridded fields are produced over the entire region, involving the Aegean, Marmara, Black and Azov Seas. The gridding is done based on

* Corresponding author

Email addresses: birol.kara@nrlssc.navy.mil (A. Birol Kara), robert.helber@nrlssc.navy.mil (Robert W. Helber), tim.boyer@nodc.noaa.gov (Timothy P. Boyer), jelsner@fsu.edu (James B. Elsner).

URL: www7320.nrlssc.navy.mil (A. Birol Kara). 
Bottom topography $(\mathrm{m})$

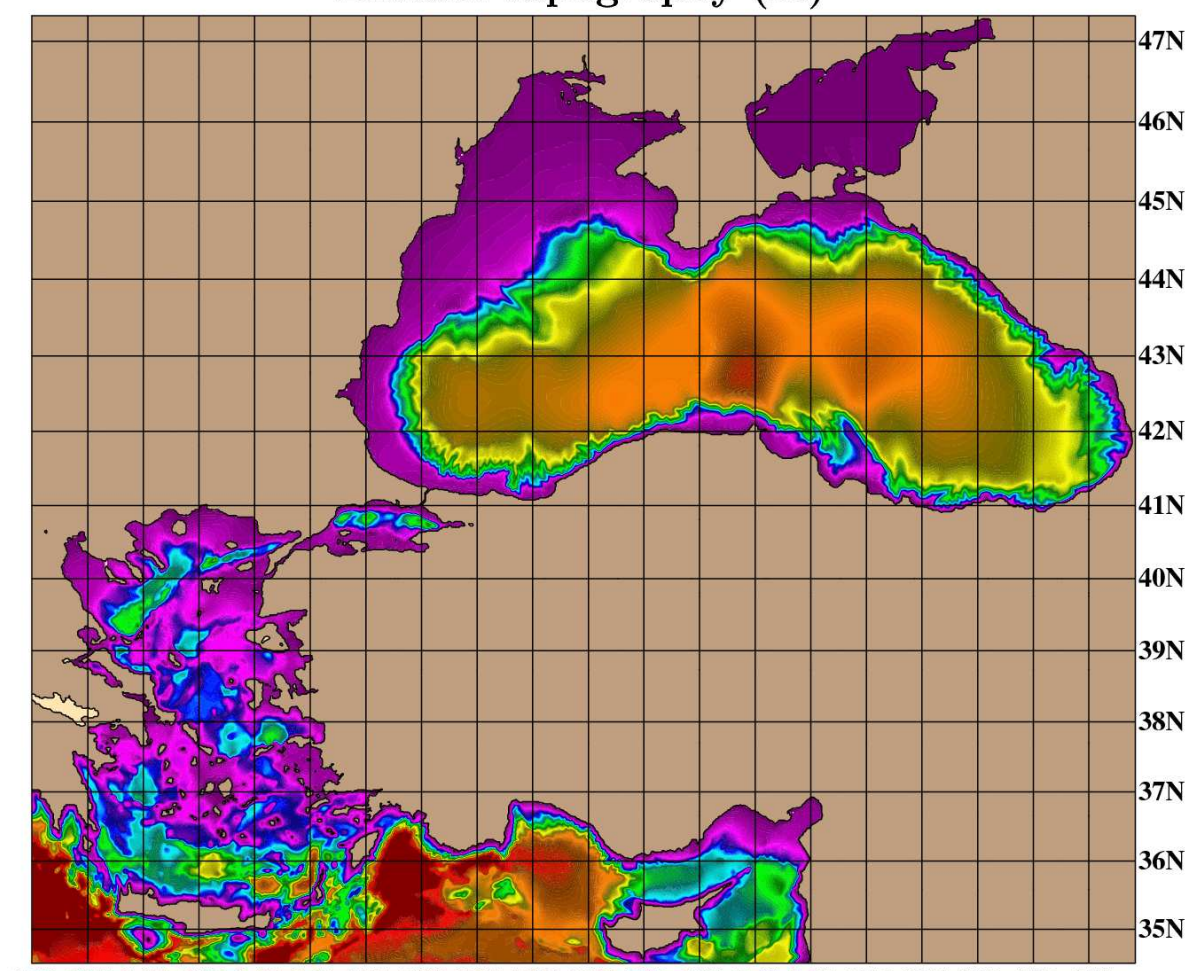

22E 23E 24E 25E 26E 27E 28E 29E 30E 31E 32E 33E 34E 35E 36E 37E 38E 39E 40E 41E

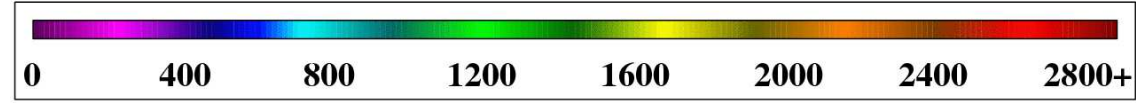

Fig. 1. Water depths in the Aegean, Marmara, Black and Azov Seas. The bottom topography is constructed from the the 1 minute resolution data from General Bathymetric Chart of the Oceans (GEBCO), which is available online at http://www.bodc.ac.uk/products/bodc_products/gebco/. In the rest of the paper, we use this domain in examining MLD feature and drop the latitude and longitude labels from figures for simplicity.

a method for interpolating MLD values from sample data using regionalized variable theory in which the prediction weights are derived from a fitted variogram model, i.e., ordinary kriging (e.g., Diggle and Ribeiro, 2007).

This paper is organized as follows. Section 2 describes $T$ and $S$ profiles in forming monthly mean MLD fields over the Aegean, Marmara, Black and Azov Seas. Section 3 gives various MLD definitions used throughout the paper. Section 4 provides an overview of spatially and temporally varying MLD fields at a grid resolution of $\left(0.25^{\circ} \times 0.25^{\circ}\right)$. Section 5 discusses differences in MLD fields obtained from various definitions. Section 6 concludes the paper.

\section{Data}

Observed profiles of historical temperature and profile pairs of temperature and salinity from three sources are used to determine MLD: These are as follows: (1) The World Ocean Database 2005 (WOD05) (Boyer et al., 2006), (2) the U. S. Navy's Master Oceanographic 
(a) Jul: Locations of $T$ profiles

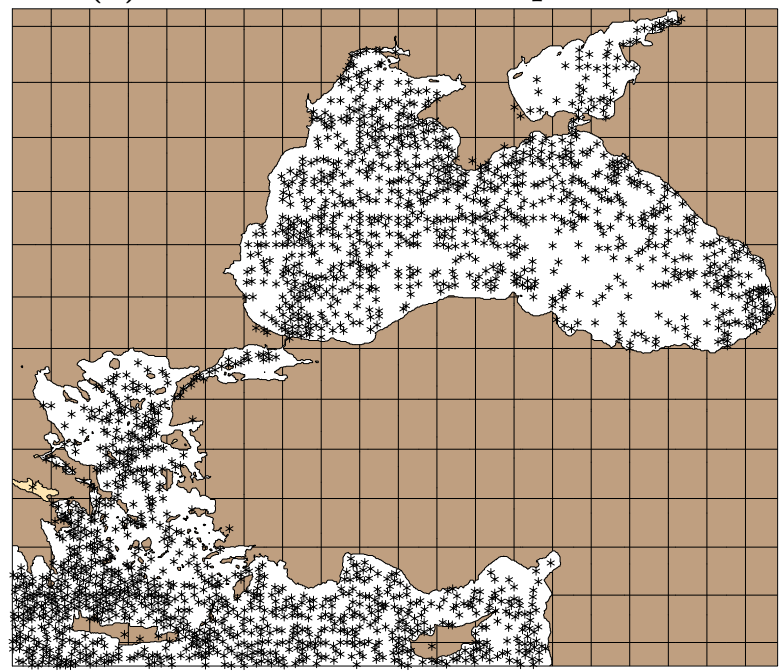

(b) Jul: Locations of $T \& S$ profiles

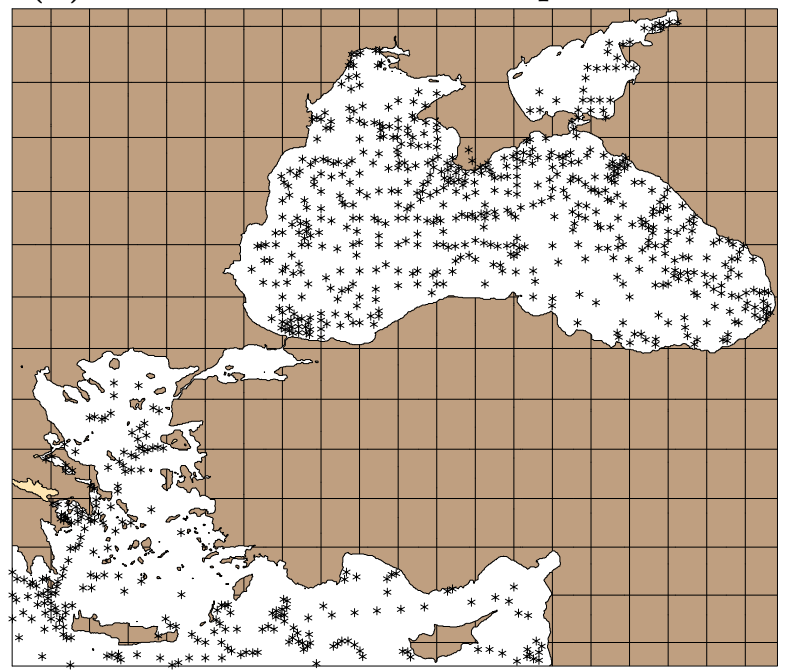

Fig. 2. Locations of profiles used for constructing the MLD climatology in July: (a) temperature-only profiles and (b) temperature and salinity profiles.

Observation Data Set (MOODS) (Teague et al., 1990), and (3) ARGO float data (Gould et al., 2004]. Currently, no temperature and salinity profiles are available from the MOODS archive in the Marmara and Azov Seas. Since data sources for MOODS and WOD05 are mostly identical, the bulk of these data are the same. In addition, the WOD05 has less stringent quality control (QC) procedures than MOODS and potentially more data sources. For these reasons, there is about a $6 \%$ increase in data volume with the addition of WOD05 data relative to the MOODS data set alone.

As an example, locations of all historical profiles are marked in Figure 2 for temperature-only and the pairs of temperature and salinity. The former profiles can be used for a temperaturebased MLD determination, and the latter ones allows computation of density and thereby a density-based MLD. The pairs of temperature and salinity profiles (958) are approximately three times less than the temperature-only profiles (3188). There are some regions where either temperature or salinity profiles are missing. Thus, there are fewer pairs of profiles.

Table 1 lists the total number of stations over three basins, including whole Agean, Marmara and Black Seas. The largest number of profiles for the whole region occur in May $(4765+4429=9194$ total $)$ with the fewest in January $(1928+3137=5065$ total $)$. The numbers are from data on the original observation depths (not standard depths) before the quality control steps described in section 4. For example, the numbers of profiles listed in Table 1 with regard to Figure 2 is obtained after the quality control steps. In particular, the superobservation step eliminates many profiles that were taken at the same location and month but in different years. The table entries labeled as high resolution are profiles that do not have any vertical gaps larger than $20 \mathrm{~m}$ in the upper $150 \mathrm{~m}$ of the profile. There are relatively less data at high vertical resolution.

Numbers in Table 1 are also given for the eastern and western parts of the Black Sea, separately. In addition to the number of profiles given in the table, we use additional 14,145 profiles in the Azov Sea for the period of 1913 through 2004. The month with the greatest 
Table 1

Total number of profiles from WOA05, MOODS and ARGO float data for three basins (whole, eastern Black Sea and western Black Sea) by data source: CTD represents profiles with $T$ and $S$ and XBT represents profiles with $T$-only. CTDhi and XBThi represent $T$ and $S$ and $T$-only profiles respectively, that have no vertical gaps larger than $20 \mathrm{~m}$ in the upper $150 \mathrm{~m}$ and are considered "high-resolution." Note that the CTDs and XBTs could be from moorings or other types of platforms. In the text they are refereed to as $T$ and $S$ profiles and $T$-only profiles, respectively.

\begin{tabular}{lrrrrrrrrrrrrr}
\hline \hline & Jan & Feb & Mar & Apr & May & Jun & Jul & Aug & Sep & Oct & Nov & Dec \\
& & \multicolumn{8}{c}{ Whole region: $\left(22^{\circ} \mathrm{E}-41.84^{\circ} \mathrm{E}, 34.5^{\circ} \mathrm{N}-47.3^{\circ} \mathrm{N}\right)$} \\
\hline CTD & 928 & 2372 & 3124 & 2973 & 4765 & 2645 & 2068 & 1901 & 1502 & 2325 & 3235 & 1902 \\
XBT & 3137 & 2633 & 3594 & 2822 & 4429 & 3631 & 4040 & 3649 & 3787 & 4162 & 3440 & 2550 \\
CTDhi & 167 & 356 & 555 & 537 & 792 & 435 & 320 & 305 & 479 & 455 & 508 & 342 \\
XBThi & 1778 & 1300 & 1566 & 1007 & 1346 & 1023 & 897 & 850 & 991 & 763 & 859 & 487 \\
\hline & & \multicolumn{7}{c}{ Eastern Black Sea: $\left(34^{\circ} \mathrm{E}-41^{\circ} \mathrm{E}, 41^{\circ} \mathrm{N}-45^{\circ} \mathrm{N}\right)$} & & \\
\hline CTD & 464 & 950 & 1076 & 1355 & 2122 & 1163 & 729 & 540 & 544 & 895 & 1185 & 810 \\
XBT & 101 & 128 & 127 & 143 & 210 & 222 & 462 & 297 & 295 & 275 & 198 & 268 \\
CTDhi & 64 & 98 & 85 & 104 & 214 & 123 & 85 & 60 & 130 & 96 & 124 & 71 \\
XBThi & 13 & 1 & 29 & 14 & 11 & 45 & 30 & 22 & 17 & 71 & 24 & 8 \\
\hline & & \multicolumn{1}{c}{ Western Black Sea: $\left(28^{\circ} \mathrm{E}-34^{\circ} \mathrm{E}, 41^{\circ} \mathrm{N}-45^{\circ} \mathrm{N}\right)$} & & \\
\hline CTD & 130 & 907 & 1003 & 1018 & 1415 & 702 & 652 & 389 & 344 & 727 & 1363 & 613 \\
XBT & 1531 & 861 & 541 & 187 & 516 & 586 & 990 & 742 & 583 & 369 & 347 & 462 \\
CTDhi & 9 & 63 & 74 & 135 & 205 & 115 & 79 & 65 & 79 & 102 & 149 & 121 \\
XBThi & 1324 & 623 & 267 & 9 & 82 & 73 & 74 & 77 & 144 & 53 & 41 & 29 \\
\hline
\end{tabular}

number of profiles is June with more than 1800 and the month with the fewest is February with less than 800. Many stations have very few vertical levels and will not be used to compute MLDs.

We should emphasize that for MLDs that require only temperature the total number of profiles can be used. Based on Table 1, there are enough profiles to construct a climatology. In addition, we have made considerable efforts to minimize the effect of non-uniform sampling, which could create structure that is not physically present, using the quality control procedures described in section 4.

The Marmara and Azov Seas are two regions where there are not many profiles to compute MLD (Figure 2). This poses problems especially when a density criterion is used for computing MLD due to relatively less number of salinity profiles. In fact, both the Marmara and Azov Seas do have many temperature and salinity data but they are mostly near the sea surface down to, say 2 or $3 \mathrm{~m}$, such as those from bottle measurements. MLD is not computed unless there is at least three depth levels in the profile. 
While the profile data we use in this paper are quality-controlled, additional errors still exist. For example tens of profiles in the Azov Sea region appear to have their latitude and longitude locations reversed putting the observations over land. It is plausible that other similar errors occur where observations from other oceans are mistakenly put in our study region. Reversing the sign of the longitude for example could put an Atlantic ocean profile in the Black Sea. Many of these types of errors have been caught in the quality control procedures of National Oceanic Data Center (NODC) or the U.S. Navy's Oceanographic Office but the state of the art of quality control procedures is not perfect. In the case of a longitude sign error, this may only be caught if the depth of the profile exceeded the bathymetric depth for the recorded location. A short profile in the Atlantic Ocean could then be misplaced to the Black Sea by passing the bathymetry check. To minimize these errors in the resulting MLD fields, outliers are removed statistically as will be described in section 4 , in detail.

\section{MLD Methodologies}

Throughout rest of the text, we use $T, S$ and $\sigma_{t}$ to denote temperature, salinity and density. Note that $\sigma_{t}=\rho-1000 \mathrm{~kg} \mathrm{~m}^{-3}$, where $\rho$ is the density of water. The density profile is computed using $T$ and $S$ values at given depths based on the standard United Nations Educational, Scientific, and Cultural Organization (UNESCO) equation of state with no pressure dependence, i.e., zero pressure (Millero and Poisson, 1981). The inclusion of pressure effects increases the density gradient sufficiently rapidly with depth that it produces a markedly shallower MLD that is strongly inconsistent with the MLDs inferred from the corresponding $T$ and $S$ profiles (e.g., Kara et al., 2000).

One of the goals of this study is to investigate the differences in MLDs calculated based on $T$-only and $T$ and $S$ in section 4 . Thus, we determine MLD based on various definitions as summarized in Table 2. $\operatorname{MLD}\left(\sigma_{T}\right)$ refers to the depth at the base of an isopycnal layer where the density has changed by an amount of

$$
\Delta \sigma_{t}=\sigma_{t}(T+\Delta T, S, P)-\sigma_{t}(T, S, P),
$$

where $P=0$, from the density at a reference depth of $3 \mathrm{~m}$. This definition takes full account of density changes due to $T$ and $S$ variations with location as described in Kara et al. (2000). Unlike the earlier studies using a constant density change of $0.125 \mathrm{~kg} \mathrm{~m}^{-3}$ (e.g., Ohno et al., 2003; Suga et al., 2004), the $\operatorname{MLD}\left(\sigma_{T}\right)$ definition involves a variable density criterion with $\Delta T$ value of $0.8^{\circ} \mathrm{C}$. While this specific $\Delta T$ value is typically suitable for mid-latitude locations (e.g., Kara et al., 2000) and subject to tuning, it is not our major focus here. The variable density definition is appropriate because $T$ generally compensates for a variable density.

The $\operatorname{MLD}\left(\sigma_{C}\right)$ definition is the depth at the base of an isopycnal layer, where the $\sigma_{t}$ value

differs from the value at the first level below $3 \mathrm{~m}$. It uses a constant threshold $\sigma_{T}$ value equal to $0.125 \mathrm{kgm}^{-3}$. On the contrary, $\operatorname{MLD}\left(\sigma_{T}\right)$ is estimated by searching for the first 
Table 2

Various MLD definitions based on $T$ and $\sigma_{T}$ through $T$ and $S$ used in this paper. The algorithms for the first three ones are available online at the web page http://www7320.nrlssc.navy.mil/nmld/nmld.html, and the last one (i.e., MLD(L)) is available at http://www.ifm-geomar.de.

\begin{tabular}{lll}
\hline \hline Methodology & Temperature & Density \\
\hline $\operatorname{MLD}\left(\sigma_{T}\right)$ & $0.8^{\circ} \mathrm{C}$ & Variable \\
$\operatorname{MLD}\left(\sigma_{C}\right)$ & $0.8^{\circ} \mathrm{C}$ & Constant \\
$\operatorname{MLD}(T)$ & $0.8^{\circ} \mathrm{C}$ & N $/ \mathrm{A}$ \\
$\operatorname{MLD}(\mathrm{L})$ & Curvature & Curvature \\
\hline
\end{tabular}

depth below $3 \mathrm{~m}$ that differs from a variable threshold $\sigma_{T}$ value, which is computed based on $T$ and $S$ profiles. Specifically, the searching threshold is equal to $\sigma_{T}$ computed at zero pressure, the reference $T$ minus $0.8^{\circ}$ and the reference $S$. The threshold is therefore variable but corresponds to a $0.8^{\circ}$ temperature change.

In the case of $\operatorname{MLD}(T)$, only $T$ profiles are used. Simply, it is the depth at the base of an isothermal layer, where the $T$ has changed by a fixed amount of $\Delta T=0.8^{\circ} \mathrm{C}$ from the temperature at a reference depth of $3 \mathrm{~m}$. Such definition generally represents an isothermal layer depth rather than $\operatorname{MLD}\left(\sigma_{T}\right)$. The difference between the two is called barrier layer (e.g., Sprintall and Tomczak, 1992).

Finally, another definition (MLD $(\mathrm{L})$ ) as introduced by Lorbecher et al. (2006) is applied. The algorithm is publicly available and used here as it is. It determines MLD by finding the first maximum of curvature of $T$ profiles. $\mathrm{MLD}(\mathrm{L})$ has the advantage that the estimated layer depth is not strongly a function of another dynamical quantities, such as the surface temperature. Unlike the other gradient-based methodologies, the methodology suggested by Lorbecher et al. (2006) does not strongly depend on seasonal and regional differences.

The threshold methodology (e.g., $\operatorname{MLD}\left(\sigma_{T}\right)$ ) accommodates the wide variety of density and temperature stratifications, such as a subsurface mixed layer underlying a surface thermal inversion; multiple fossil layers beneath the surface mixed layer. The threshold methodology, however, is limited in that it amounts to a bulk computation. That will return the layer most closely associated with a seasonal MLD. The curvature methodology, on the other hand, is a measure of the most near surface curvature peak and therefor always returns the shallowest measurable MLD, which for high resolution profiles could be the diurnal MLD as explained by Helber et al. (2008).

As an application of all MLD definitions mentioned above, we present $T$ and $S$ and calculated density profiles at $\left(43.1^{\circ} \mathrm{N}, 29.8^{\circ} \mathrm{E}\right)$ located in the Black Sea on February of 1982 (Figure 3). Based on these profiles $\operatorname{MLD}\left(\sigma_{T}\right)$ and $\operatorname{MLD}\left(\sigma_{C}\right)$ are almost identical with values of $46 \mathrm{~m}$ and $48 \mathrm{~m}$. The temperature-only criterion, i.e., $\operatorname{MLD}(T)$, results in deeper value of $71 \mathrm{~m}$. The curvature-based MLD $(\mathrm{L})$ definition gives a value of $46 \mathrm{~m}$ at this particular location, which is consistent with $\operatorname{MLD}\left(\sigma_{T}\right)$ and $\operatorname{MLD}\left(\sigma_{C}\right)$. Note that while the MLD of $46 \mathrm{~m}$ is at the top of the thermocline, the MLD of $71 \mathrm{~m}$ is at the bottom of the thermocline. The top 


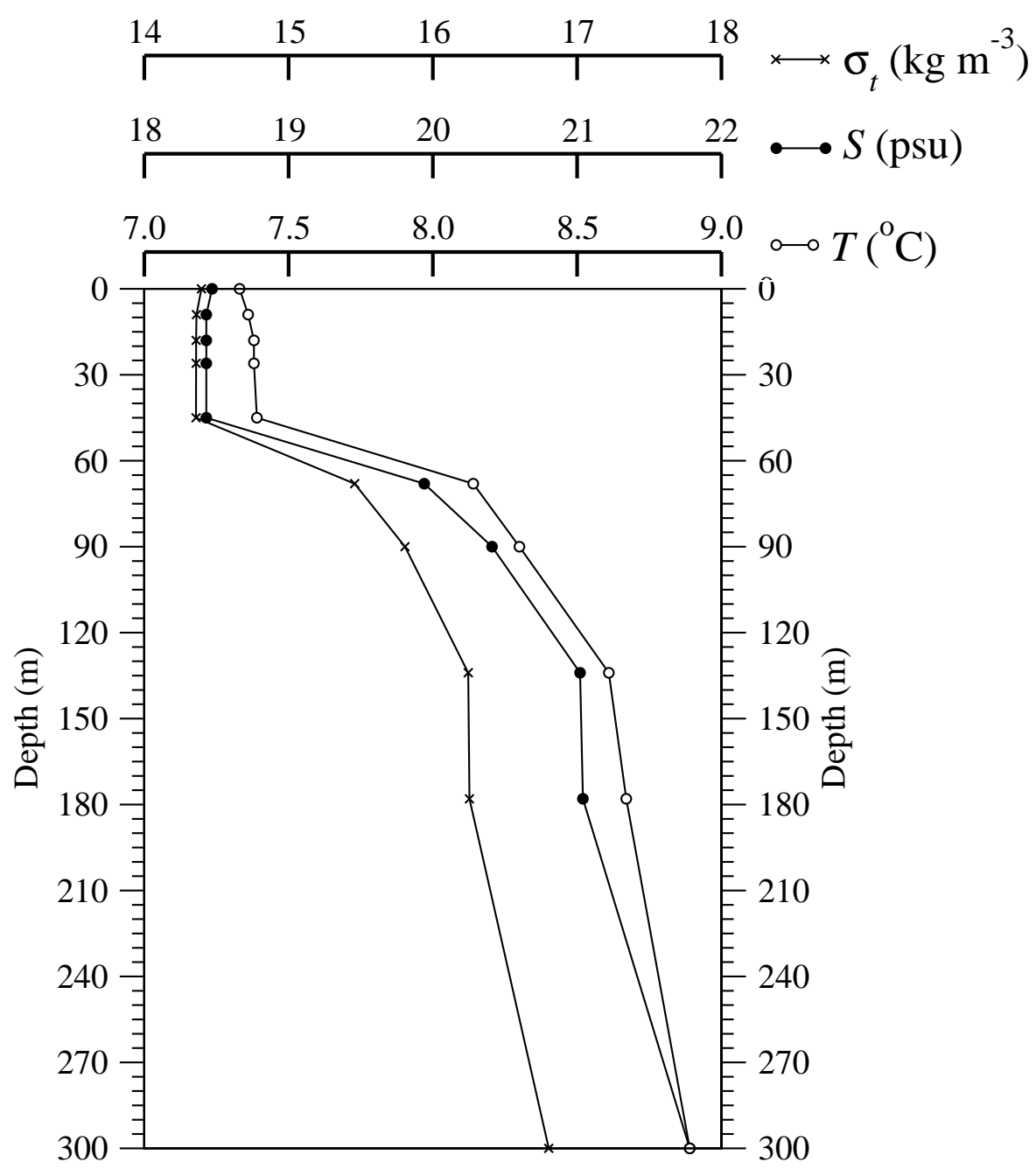

Fig. 3. Vertical profiles of $T, S$ and density at $\left(43.1^{\circ} \mathrm{N}, 29.8^{\circ} \mathrm{E}\right)$ on 11 February 1982 . The $T$ and $S$ profiles are from the WOD05 data set, and density was computed with UNESCO equation of state with no pressure dependence, as explained in the text. Profiles were taken at a local time of 12 GMT.

of the thermocline is what one would consider the end of the truly well mixed layer. At this particular location, there is an indication of the barrier layer $(25 \mathrm{~m})$ since $\operatorname{MLD}\left(\sigma_{T}\right)$ is different than $\operatorname{MLD}(T)$.

\section{Monthly MLD Climatology}

As mentioned in section 2, there can be some outliers in the $T$ and $S$ profiles from WOD05, MOODS and ARGO floats. In addition, the historical observations represent an unknown underlying process and contain unavoidable noise when attempting to construct a climatology. The noise can be the result of various factors, for example, inter-annual variability, systematic and random errors, and inhomogeneous sampling. Thus, we first explain how the errors in resulting MLD fields due to improper profiles are reduced before presenting spatial variations of monthly climatologies. 
There are three steps to reduce outliers in the MLD fields. We only provide a brief description as follows. The first one is the Z-score statistics, as described by Lanzante (1996), which is applied to normalize MLD values using the bi-weight mean and standard deviation. For example, as evident from Table 1, the large relative drop in numbers for the high resolution profiles indicates that many of the profiles used in the analysis have relatively large gaps in the upper $150 \mathrm{~m}$. If large vertical gaps produce a very large MLDs in a few profiles randomly, then the Z-score statistics removes these outliers.

The second step for reducing outlier includes climatological super-observations, representing the median value and location of MLDs from all years for a given month that are within a $1 / 12^{\circ}$ circle. Since the gridded resolution is $1 / 4^{\circ}$ there will be up to four super-observations for two adjacent gridded data points. A set of super-observations are computed by iterating through all the original observations and replacing them with super-observations. The final step is to apply a median filter (e.g., Perreault and Hebert, 2007). This is done for replacing its value with the median of the surrounding observations but without altering the location of the observations. Further details about each one of these steps are provided in Helber et al. (this issue).

The method of kriging is applied to obtain MLD fields at a resolution of $0.25^{\circ} \times 0.25^{\circ}$. Kriging is a set of linear regression routines which minimize estimation variance from a predefined covariance model (Diggle and Ribeiro, 2007). The methodology is based on the assumption that irregularly placed MLD values are treated regionally. The regionalized MLD then becomes intermediate between a truly random variable and a completely deterministic variable. The kriging methodology takes the spatial correlations into the account for MLDs near each other; MLDs that are widely separated are statistically independent. Details of the kriging procedure applied in this study are provided in the appendix. Note that the approach that we have been using is to pre-process the data, so that all observations have the same error level. That is the purpose of the super-observation and median filter steps as described earlier.

We now introduce the seasonal cycle of $\operatorname{MLD}\left(\sigma_{T}\right)$ over the Aegean, Marmara, Black and Azov Seas (Figure 4). A MLD value of $>200 \mathrm{~m}$ is seen in the Aegean Sea during winter, but it becomes as shallow as $25 \mathrm{~m}$ during summer. Seasonal variability is also evident in the Black Sea. Shallow MLDs in the Black Sea can be attributed to attenuation of solar radiation during summer months (Kara et al. 2005). There are also some significant variations in MLD in the Marmara Sea but much less variation in the Azov Sea, where water depth is already very shallow. As mentioned earlier, the lack of $T$ and $S$ profiles in these two regions in comparison to others also limits the accuracy of derived MLD features.

MLDs are generally deeper by 100-150 m in the Aegean Sea than in the Black Sea. Deep MLDs of $>200 \mathrm{~m}$ seen in the western part of the Aegean Sea do not exist anywhere in Black Sea at all. In fact, the entire northern Levant and the southern Aegean region represents the locations of intermediate and deep water formation and depending on the severity of winter conditions, MLDs can be as deep as 400-500 m. The MLD of 200-300 $\mathrm{m}$ is a typical case during the years with weak convection. This structure has also some spatial variability. For example, the Rhodes region with a permanent cyclonic gyre has always deeper mixed layer than regions located further east. 

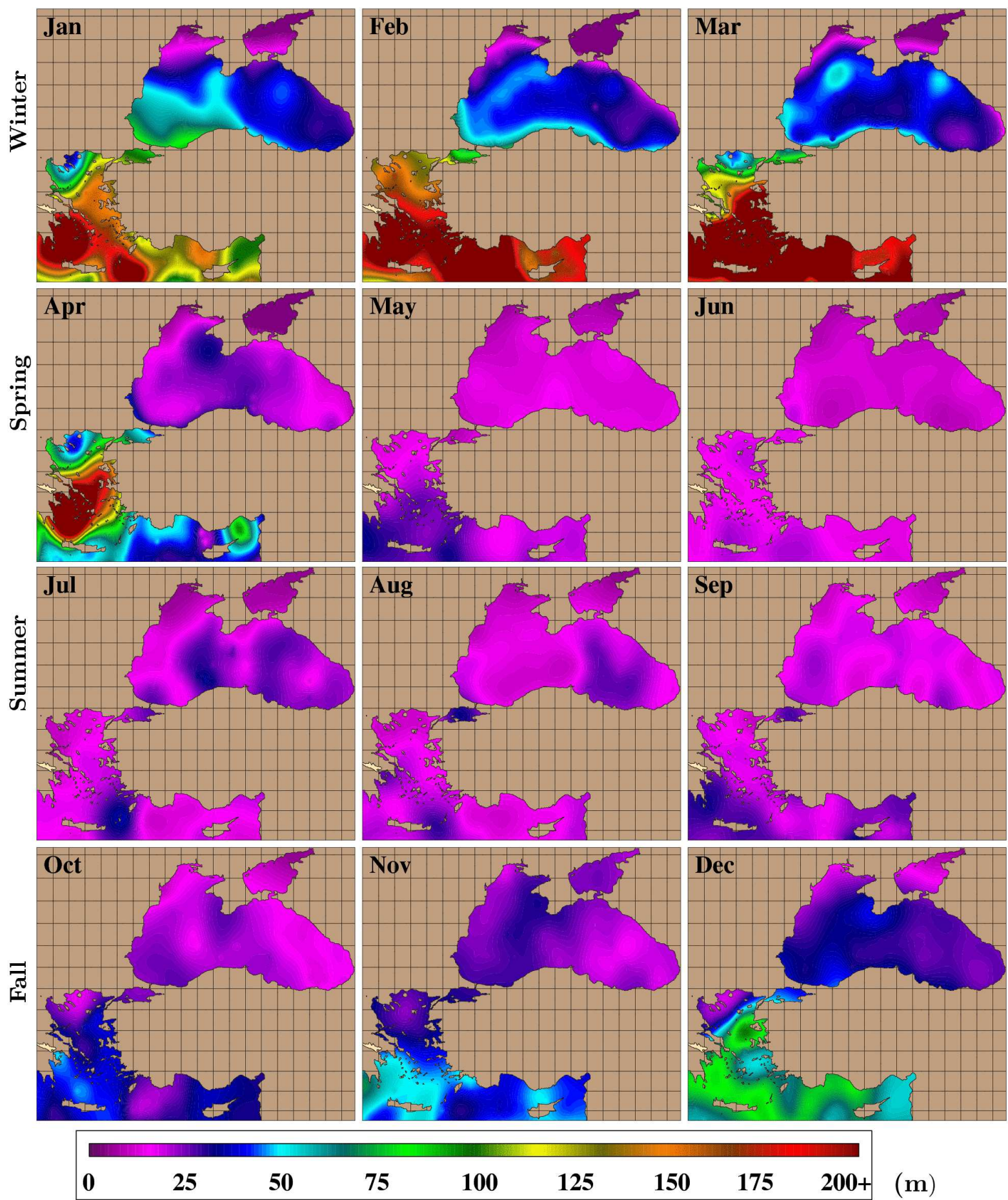

Fig. 4. Monthly mean MLD climatology constructed at a $0.25^{\circ} \times 0.25^{\circ}$ grid resolution. The MLD methodology uses a variable density criterion as described in the text. We use $T$ and $S$ profiles from both WOA05, MOODS and ARGO data archives in computing MLDs.

Unlike the Mediterranean Sea, there is generally strong density stratification in Black Sea, typically limiting the depth of MLD and resulting in shallower values. MLD rarely exceeds $50 \mathrm{~m}$ in the Black Sea during winter, and is very shallow $(<20 \mathrm{~m})$ during spring and summer. Starting from November, the deepening in MLD picks up in the Black Sea. Previously, Kara et al. (2008) demonstrated that precipitation contributes to the spring-summer buoyancy 
and the existence of shallow mixed layer formation. This results in reduced turbulent mixing in the Black Sea. Note also that MLDs in the Azov Sea are slightly deeper during winter in comparison to other seasons. A striking feature of the monthly MLD fields is the existence of Caucasus and Sevastopol anticyclonic eddies in the Black Sea.

\section{Differences Among MLD Definitions}

Similar to the $\operatorname{MLD}\left(\sigma_{T}\right)$ definition that includes a variable density criterion, we apply other methodologies listed in Table 2 to produce monthly mean fields. This is done for comparisons of fields. Our purpose is to find out whether or not there are significant differences in the MLD fields depending on the criterion used. Note that $\operatorname{MLD}\left(\sigma_{T}\right)$ and $\operatorname{MLD}\left(\sigma_{C}\right)$ are computed based on profiles of $T$ and $S$, while $\operatorname{MLD}(T)$ and $\operatorname{MLD}(\mathrm{L})$ are computed using profiles of $T$ only. Processing of the monthly fields is same for all MLD definitions.

\subsection{Climatological Fields}

Climatologies of monthly MLD fields computed based on different definitions are presented in Figure 5 for January. There are no large differences in MLD fields obtained by $\operatorname{MLD}\left(\sigma_{T}\right)$ versus $\operatorname{MLD}\left(\sigma_{C}\right)$ and $\operatorname{MLD}(T)$. Major differences arise when using $\operatorname{MLD}(\mathrm{L})$ which computes the MLD based on the first curvature peak of near surface density or $T$ profiles. A comparison of mean fields based on $\operatorname{MLD}\left(\sigma_{T}\right)$ versus $\operatorname{MLD}\left(\sigma_{C}\right)$ indicates that use of the variable density criterion rather than the constant density criterion does not change MLD significantly, except in the Aegean Sea (Figure 5a,b). However, shoaling of MLD does also occur at some parts of the Black Sea when using $\operatorname{MLD}\left(\sigma_{C}\right)$ as opposed to $\operatorname{MLD}\left(\sigma_{T}\right)$

The impact of salinity in determining the MLD is evident from comparisons of fields based on $\operatorname{MLD}\left(\sigma_{T}\right)$ versus $\operatorname{MLD}(T)$ as shown in (Figure 5a,c). The impact of salinity stratification is to make MLDs shallower. This is evident in all regions. The MLD(L) gives much shallower depths in comparison to those obtained from others (Figure 5d). This is particularly true for July in the Aegean Sea as well (Figure 6).

Some noise in monthly fields also exists in July, regardless of which MLD definition is used. While there are many $T$ and $S$ profiles in this particular month (see Figure 2), the number of data points alone does not ensure that the field is sampled well enough. It often occurs that in one year there will be a large number of observations in a certain location and then no observations for many years in that same location. If that one year was anomalous the result is a bull's eye. There may be many observations but the field may still be poorly sampled. That is a problem that generally exists in historical observations. ARGO is one observational platform that is helping even out the sampling in this way.

In general, MLD(L) values are still relatively shallow in July (Figure 6). The algorithm by Lorbacher et al. (2006) looks for an isothermal layer at the surface. It determines what is isothermal based on the variance within the profile. In the winter, when the entire water 
(a) Jan: $\operatorname{MLD}\left(\sigma_{T}\right)$

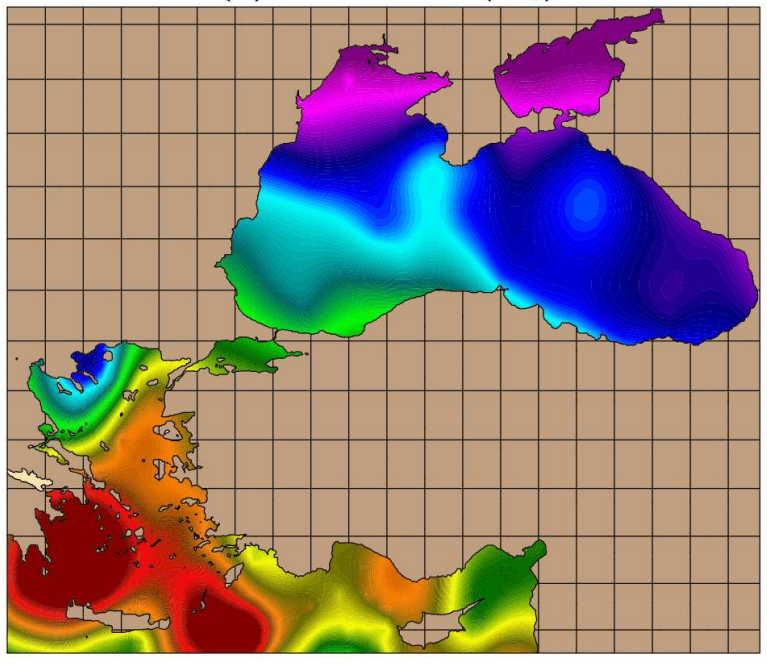

(c) Jan: $\operatorname{MLD}(T)$

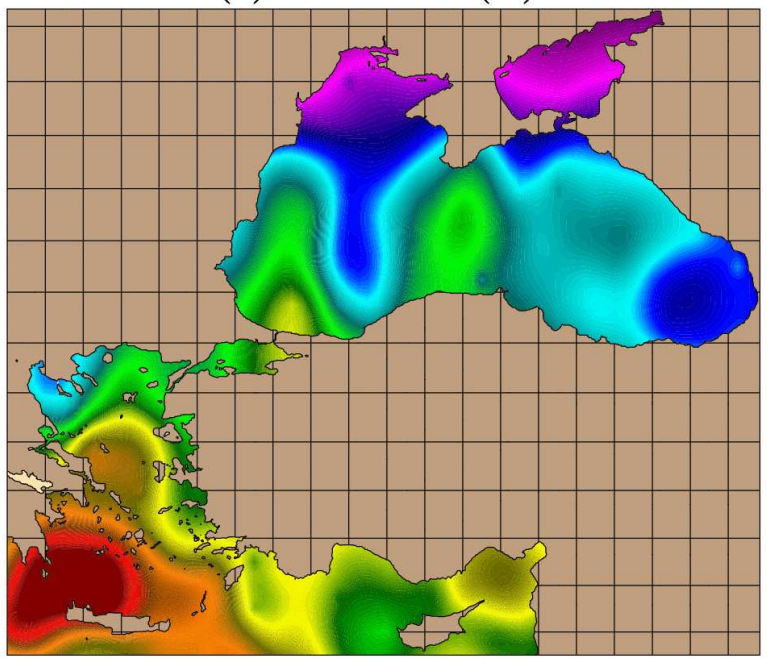

(b) Jan: $\operatorname{MLD}\left(\sigma_{C}\right)$

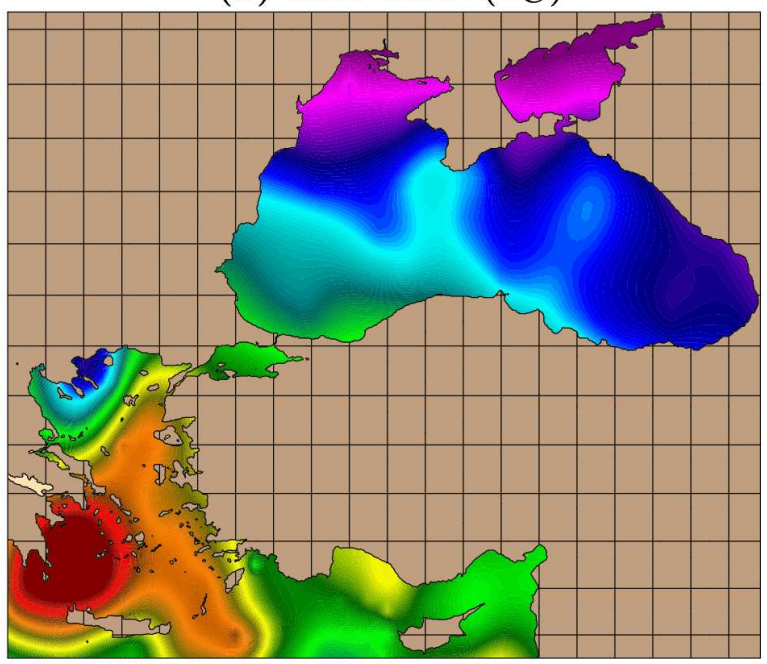

(d) Jan: $\operatorname{MLD}(\mathrm{L})$

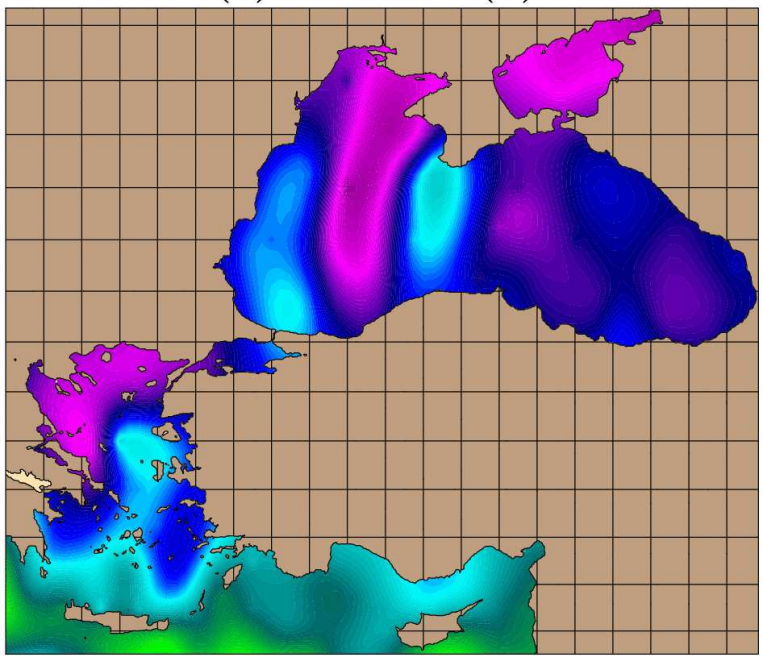

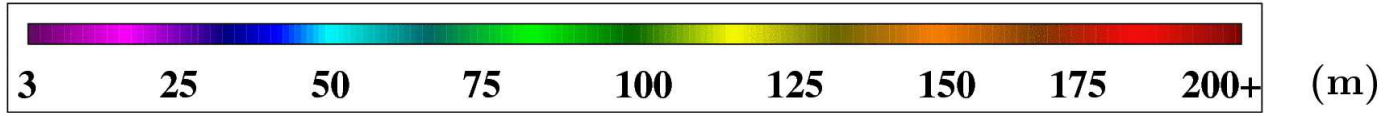

Fig. 5. Spatial variability of climatological MLDs in January as obtained from four different methodologies listed in Table 2.

column is well mixed and the variance of the profile is uniform throughout, the algorithm cannot find an isothermal layer with variance less than deeper in the profile. In that case, the algorithm results in very shallow values and even $<5 \mathrm{~m}$. In addition, it is noted that the original algorithm for $\mathrm{MLD}(\mathrm{L})$ does not impose a minimum depth value to determine the MLD. This may result in MLD values of $<1 \mathrm{~m}$. For this reason, and to be consistent with other definitions we specified a minimum MLD value of $3 \mathrm{~m}$ in finding MLD(L) values. Lorbacher et al. (2006) also introduced a definition which is similar to what we use here, but density profiles are input to the algorithm. We did not make further comparisons against the curvature-based $\mathrm{MLD}(\mathrm{L})$ algorithm for the purpose of this paper.

Overall, one thing to note from MLD fields in July is the existence of a few bull's eyes which are due to sampling variation. In particular, the bull's eyes are in the original data. They are due to geophysical errors, i.e., they arise due to regional variability that is not properly 
(a) Jul: $\operatorname{MLD}\left(\sigma_{T}\right)$

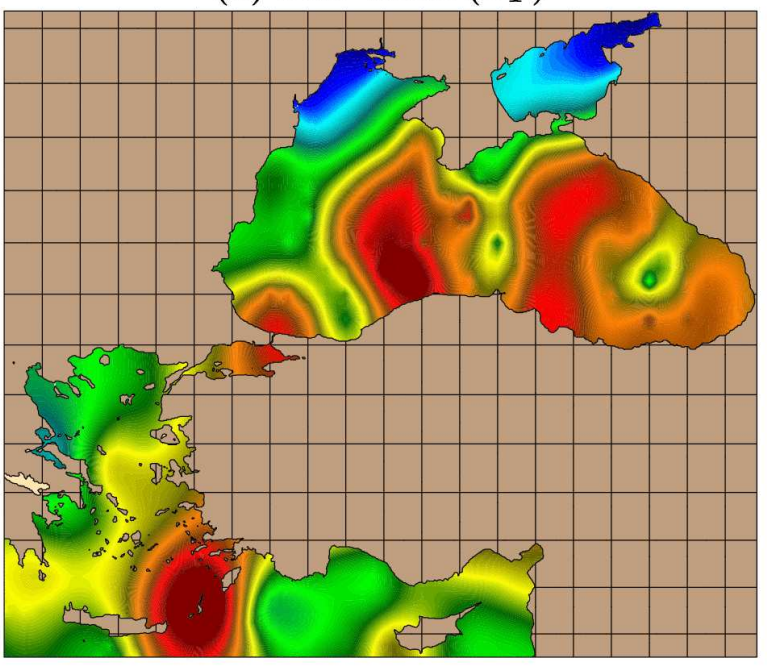

(c) Jul: $\operatorname{MLD}(T)$

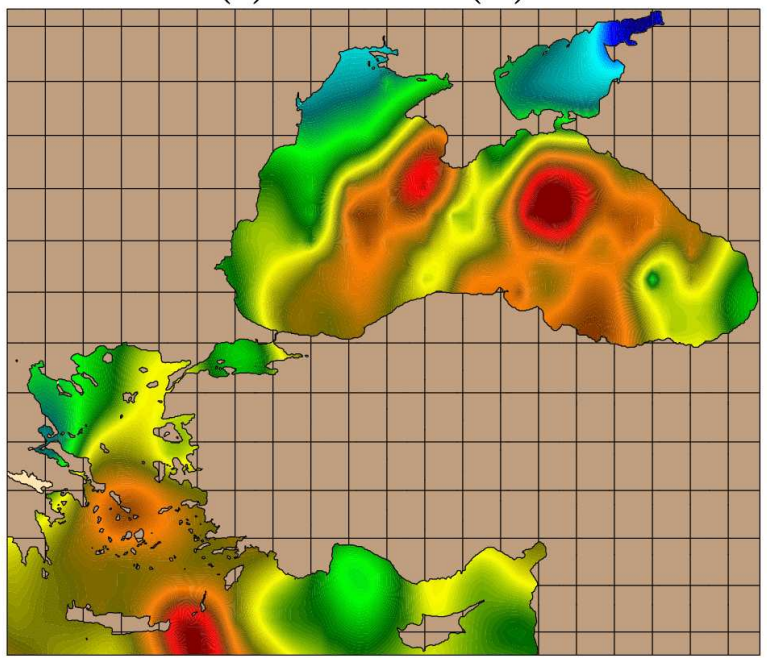

(b) Jul: $\operatorname{MLD}\left(\sigma_{C}\right)$

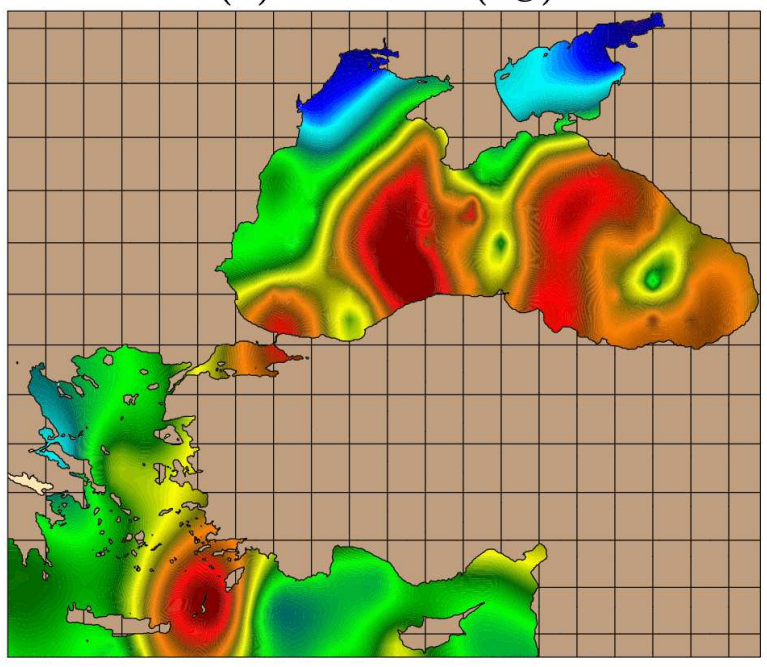

(d) Jul: $\operatorname{MLD}(\mathbf{L})$

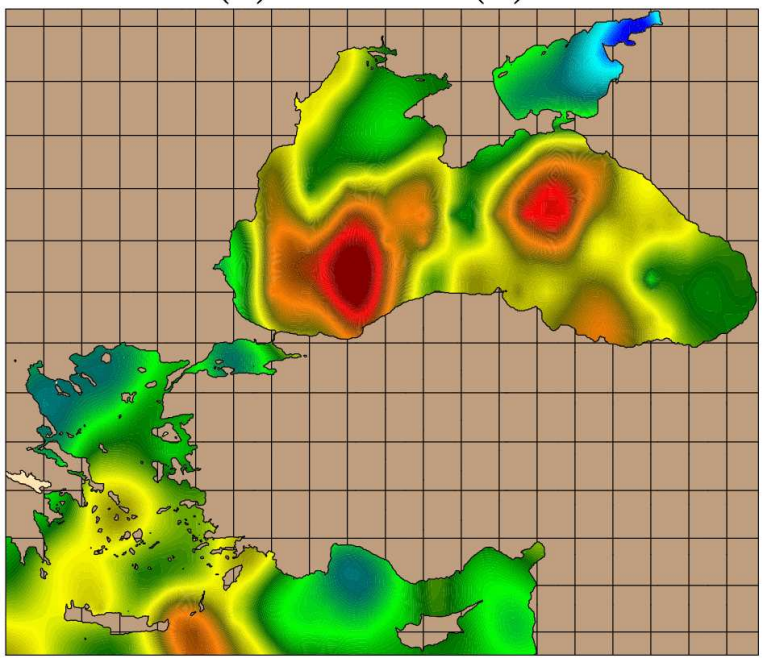

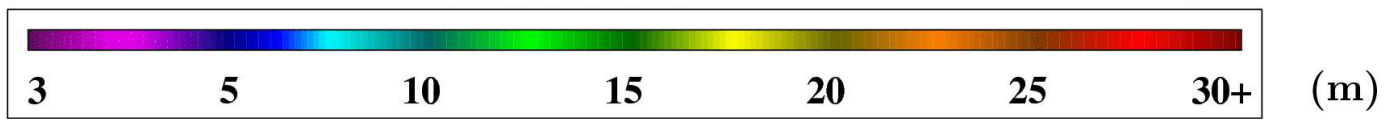

Fig. 6. The same as Figure 5 but for July.

sampled. They mainly occur when observations are made during a relatively rare event that is not observed again. The median filter may enhance these by preserving the edge that forms around them. On the other hand, at least for the case of Black Sea, the bull's eyes could be representing different quasi-permanent eddies sampled during the field surveys. There are plenty of such features within the Black Sea, and some of them are smoothed out during the construction of climatology and some are not and stay there resembling bull's eyes.

To provide further insight about differences in MLD fields obtained from the definitions listed in Table 2, time series of monthly mean MLDs are examined at two locations. We randomly chose two locations, one of which is located at $\left(43^{\circ} \mathrm{N}, 30^{\circ} \mathrm{E}\right)$ in the western Black Sea, and the other of which is located at $\left(39^{\circ} \mathrm{N}, 24^{\circ} \mathrm{E}\right)$ in the western Aegean Sea. Variations in MLD are clearly evident at $\left(43^{\circ} \mathrm{N}, 30^{\circ} \mathrm{E}\right)$ over the seasonal cycle (Figure 7$)$. MLD $(T)$ gives deeper depths than others during winter, and $\operatorname{MLD}(\mathrm{L})$ has the shallowest values over the 


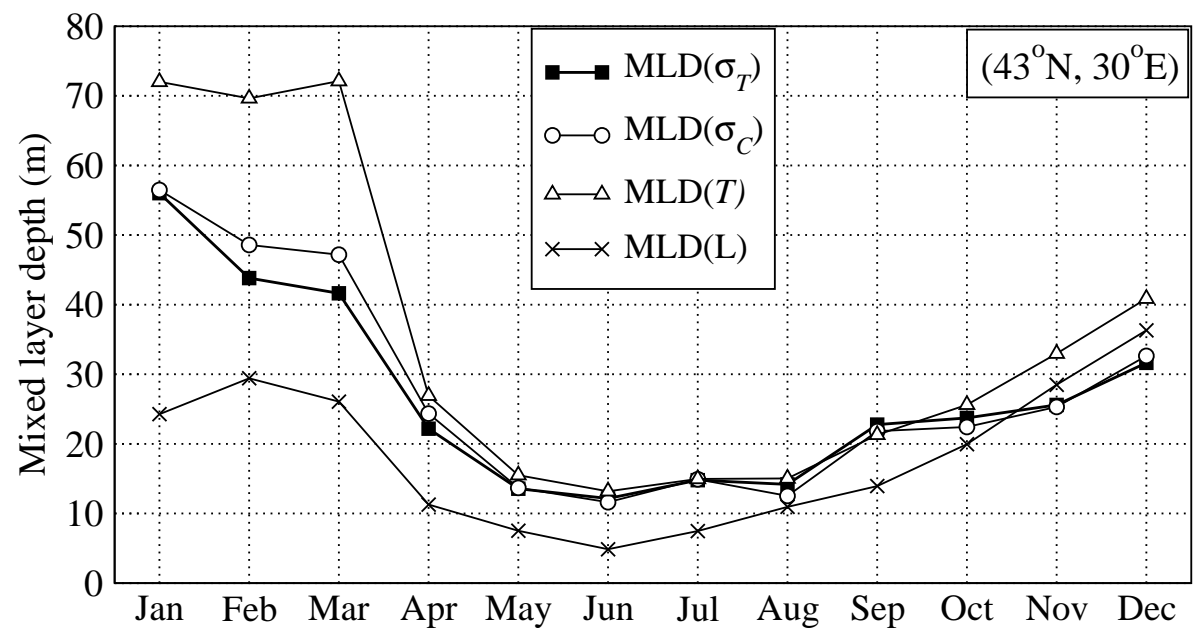

Fig. 7. Time series of monthly mean climatological MLD as obtained from various definitions at $\left(43^{\circ} \mathrm{N}, 30^{\circ} \mathrm{E}\right)$.

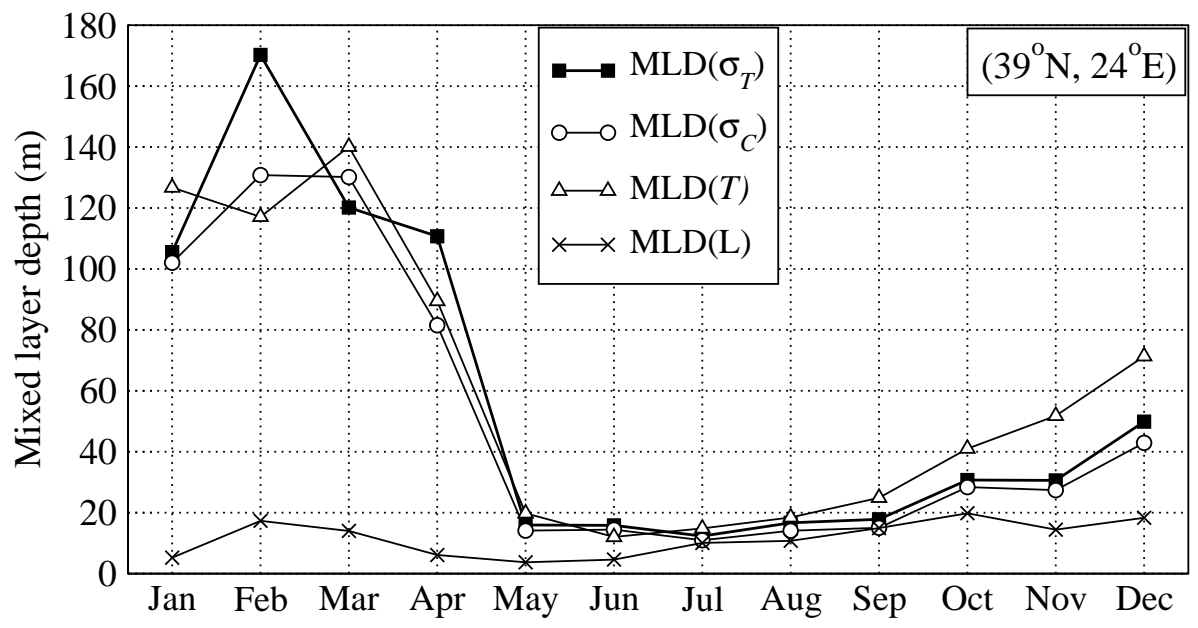

Fig. 8. The same as Figure 7 but at $\left(39^{\circ} \mathrm{N}, 24^{\circ} \mathrm{E}\right)$.

seasonal cycle. The most striking feature of MLDs is evident at $\left(39^{\circ} \mathrm{N}, 2^{\circ} \mathrm{E}\right)$ where $\mathrm{MLD}(\mathrm{L})$ is significantly different than others from January through April (Figure 8). In fact, depths obtained from the MLD $(\mathrm{L})$ definition is again shallow by $\approx 100 \mathrm{~m}$. This is because the water column is relatively uniform for the entire depth of the profiles, and the MLD(L) algorithm is unable to distinguish an isothermal layer from the variance of the entire profile thereby assuming that the isothermal layer is shallow or non-existent.

The southeastern Aegean Sea typically has very shallow values when using the curvaturebased $\operatorname{MLD}(\mathrm{L})$ criterion, but relatively deep ones when using $\operatorname{MLD}\left(\sigma_{T}\right)$ and $\operatorname{MLD}\left(\sigma_{C}\right)$. As an example of why MLD(L) gives very different values, we examine $T, S$ and density profiles at $\left(37.2^{\circ} \mathrm{N}, 23.7^{\circ} \mathrm{E}\right)$ on 4 January 1990 (Figure 9), demonstrating an example of a well mixed wintertime structure. $\operatorname{MLD}\left(\sigma_{T}\right)$ and $\operatorname{MLD}\left(\sigma_{C}\right)$ have values of $238 \mathrm{~m}$ and $205 \mathrm{~m}$, respectively. These are much shallower than $400 \mathrm{~m}$, which is what the temperature-only criterion of $\operatorname{MLD}(T)$ gives. The shallowest value is $34 \mathrm{~m}$ obtained from the MLD(L) definition, which appears to be more realistics. This is because the profiles indicate a slightly warmed thin surface layer (with surface $T$ of $15.3^{\circ} \mathrm{C}$ and $\sigma_{t}$ of $28.9 \mathrm{~kg} \mathrm{~m}^{-3}$ ) on top of a previously 


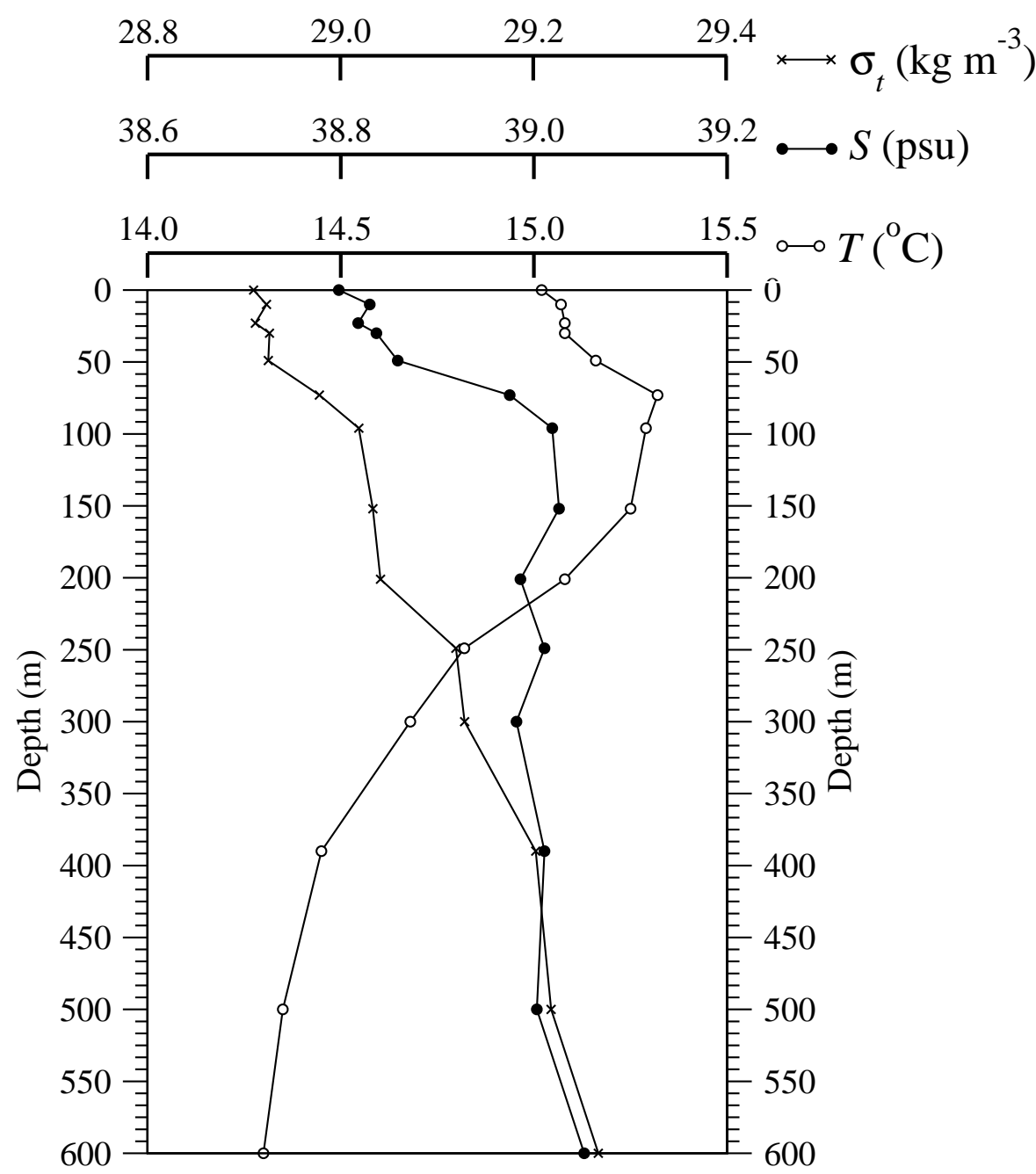

Fig. 9. Vertical profiles of $T, S$ and density at $\left(37.2^{\circ} \mathrm{N}, 23.7^{\circ} \mathrm{E}\right)$ on 4 January 1990 . The $T$ and $S$ profiles are from the WOD05 data set, and density was computed with UNESCO equation of state with no pressure dependence, as explained in the text. Profiles were taken at the local time of 15 GMT.

generated homogeneous layer. These two water masses are separated by the temperature and density differences smaller than the criteria set in the analysis. Thus, clearly it is possible to obtain misleading information about MLD features in the region, depending on using either a curvature method or threshold method.

Since the temperature range of this profile is $<1.5^{\circ} \mathrm{C}$ over a depth of $600 \mathrm{~m}$, this can be considered a very well mixed ocean. At a depth of $\approx 20 \mathrm{~m}$ there is a density inversion. Due to penetrative convection the effective mixed layer depth may be much deeper than the profile itself. For these reasons, none of the MLD methods are particularly accurate. The MLD(L) method, however, is deceptively shallow. Since the MLD(L) measures the curvature variability of the profile it tends to be shallow in profiles that are well mixed because it is unable to distinguish an isothermal layer from the relative uniformity over the whole profile. 

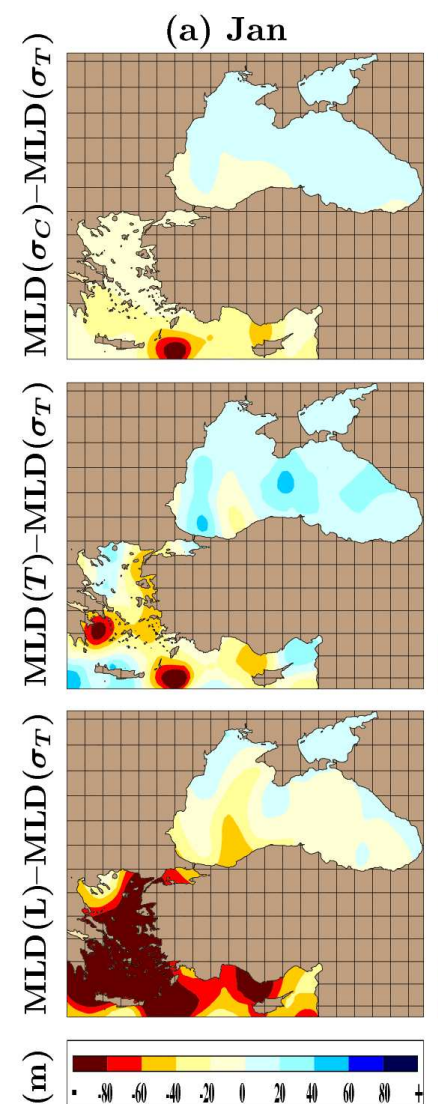

(b) Apr

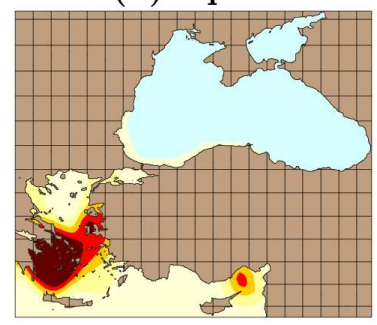

(c) Jul
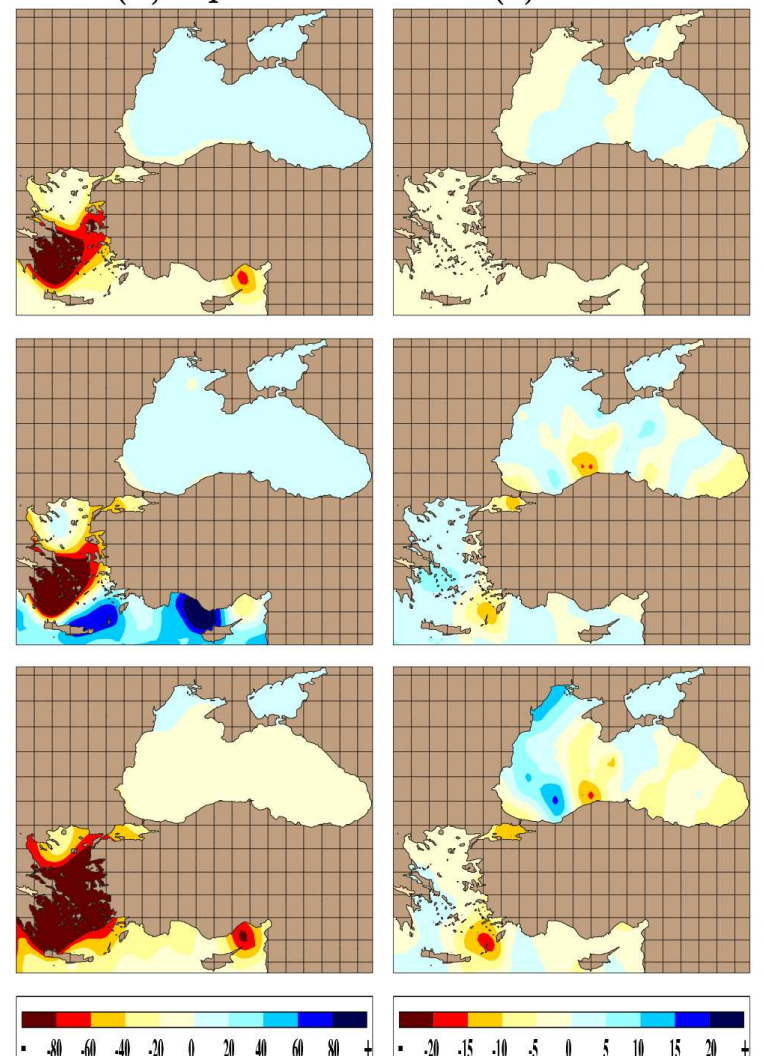
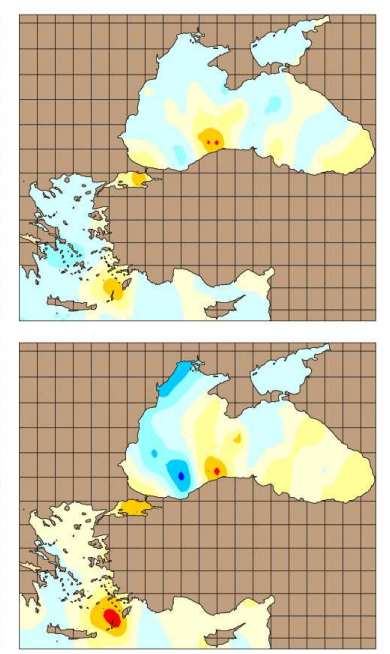

- 2. (d) Oct
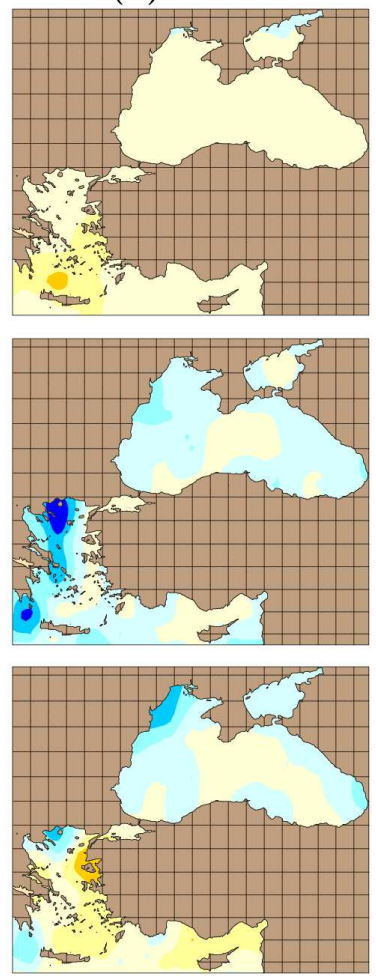

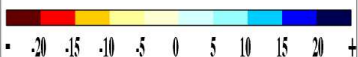

Fig. 10. Differences in MLDs calculated using the variable density criterion (i.e., $\operatorname{MLD}\left(\sigma_{T}\right)$ ) in comparison to $\operatorname{MLD}(T)$ and $\operatorname{MLD}(\mathrm{L})$. Monthly mean differences are shown in January, April, July and October. In all cases, $\operatorname{MLD}\left(\sigma_{T}\right)$ is subtracted from others. Note that color palettes are different.

\subsection{Statistical Comparisons of $M L D$}

Monthly mean values obtained from $\operatorname{MLD}\left(\sigma_{C}\right), \operatorname{MLD}(T)$ and $\operatorname{MLD}(\mathrm{L})$ are compared with those from $\operatorname{MLD}\left(\sigma_{T}\right)$, which is based on the density-based criterion over the Aegean, Black, Marmara and Azov Seas over the seasonal cycle. Our purpose is to quantify differences among MLD values. First, monthly mean differences are evaluated. Differences are formed at each grid points, and then spatial maps are obtained (Figure 10). Differences in MLD with respect to $\operatorname{MLD}\left(\sigma_{T}\right)$ are typically small in all months, especially in summer. As expected, large differences arise during winter when MLD is deep. The most obvious feature of the differences in MLD values is that the $\mathrm{MLD}(\mathrm{L})$ gives much shallower values $(>50 \mathrm{~m})$ than $\operatorname{MLD}\left(\sigma_{T}\right)$ in the Aegean Sea in January and April (Figure 10a,b). MLDs from all algorithms agree with those from $\operatorname{MLD}\left(\sigma_{T}\right)$ quite well during July and October (Figure 10c,d).

MLD fields from $\operatorname{MLD}\left(\sigma_{C}\right), \operatorname{MLD}(T)$ and $\operatorname{MLD}(\mathrm{L})$ are further evaluated based on more comprehensive statistical metrics. Since winter MLDs are usually much deeper than summer MLDs, and there can be geographical differences in MLDs (i.e., deep ones in the Aegean Sea and shallower ones in the Black Sea), we will also use a non-dimensional statistical metric for fair comparisons of fields. This is needed since there will be a skewed distribution for MLD values, i.e., much larger deviations above the mean than below the mean. This can 
depend on the season and time of the year.

The statistical metrics used for comparing MLD time series are mean error (ME), correlation coefficient $(R)$ and non-dimensional skill score $(\mathrm{SS})$. Let $X_{i}(i=1,2, \cdots, n)$ be the set of $n$ reference $\operatorname{MLD}\left(\sigma_{T}\right)$ values, and let $Y_{i}(i=1,2, \cdots, n)$ be the set of corresponding values of MLDs from each one of other algorithms, i.e., $\operatorname{MLD}\left(\sigma_{C}\right), \operatorname{MLD}(T)$ and $\operatorname{MLD}(\mathrm{L})$. Also let $\bar{X}(\bar{Y})$ and $\sigma_{X}\left(\sigma_{Y}\right)$ be the mean and standard deviations of the reference (other methodology) values, respectively. Following Murphy (1995), the preceding statistical measures can be expressed as follows:

$$
\begin{aligned}
\mathrm{ME} & =\bar{Y}-\bar{X}, \\
R & =\frac{1}{n} \sum_{i=1}^{n}\left(X_{i}-\bar{X}\right)\left(Y_{i}-\bar{Y}\right) /\left(\sigma_{X} \sigma_{Y}\right), \\
\mathrm{SS} & =R^{2}-\underbrace{\left[R-\left(\sigma_{Y} / \sigma_{X}\right)\right]^{2}}_{B_{\text {cond }}}-\underbrace{\left[(\bar{Y}-\bar{X}) / \sigma_{X}\right]^{2}}_{B_{\text {uncond }}} .
\end{aligned}
$$

In the time series comparisons, $n$ is equal to 12 , i.e., we have monthly mean MLD time series at given grid point over the seasonal cycle (January through December). ME is obtained by subtracting values from $\operatorname{MLD}\left(\sigma_{T}\right)$ from those from each one of other methodologies. It simply represents climatological mean difference with respect to MLD values obtained from the $\operatorname{MLD}\left(\sigma_{T}\right)$ definition. $R$ value is a measure of the degree of linear association between the time series.

The SS in Eq. (4) is the fraction of variance explained by two non-dimensional biases (conditional bias, $B_{\text {cond }}$, and unconditional bias, $\left.B_{\text {uncond }}\right)$ which are not taken into account in the $R$ formulation (see $(3)$ ). In brief, $B_{\text {uncond (also called systematic bias) is a non-dimensional }}$ measure of the difference between the means of the time series, while $B_{\text {cond }}$ is a measure of the relative amplitude of the variability in the two data sets. Note that $R^{2}$ is equal to SS only when $B_{\text {cond }}$ and $B_{\text {uncond }}$ are zero. These two biases are never negative. SS is 1.0 for perfect agreement, and is negative for $B_{\text {cond }}+B_{\text {uncond }}>R^{2}$.

Figure 11 provides spatial fields of ME, $R$ and SS, all of which were calculated over the seasonal cycle. In comparison to $\operatorname{MLD}\left(\sigma_{T}\right)$, climatological mean MLD bias for $\operatorname{MLD}\left(\sigma_{C}\right)$ and $\operatorname{MLD}(T)$ is small within \pm 10 m over most of the region (Figure 11a). The only exception is the mean biases from the $\mathrm{MLD}(\mathrm{L})$ criterion, giving too shallow values in the Aegean Sea. On the contrary, seasonal cycle of MLD from all definitions agree with each other well. This is evident from correlation values close to almost 1 all over the region, even for the MLD(L) criterion (Figure 11b). Thus, MLD seasonal cycle is robust regardless of which definition is preferred. However, such agreement in $R$ values does not identify the differences in means and standard deviations of MLD time series from two given methodologies as mentioned above.

Given the deep (shallow) MLD value during winter(summer), the non-dimensional skill score, which takes conditional and unconditional biases into the account, provides better information about the relationship between MLD pairs. In computing skill values the logarithmic transformation is applied to each of the 12 monthly MLD fields at every grid point. The 
(a) Mean bias (m)
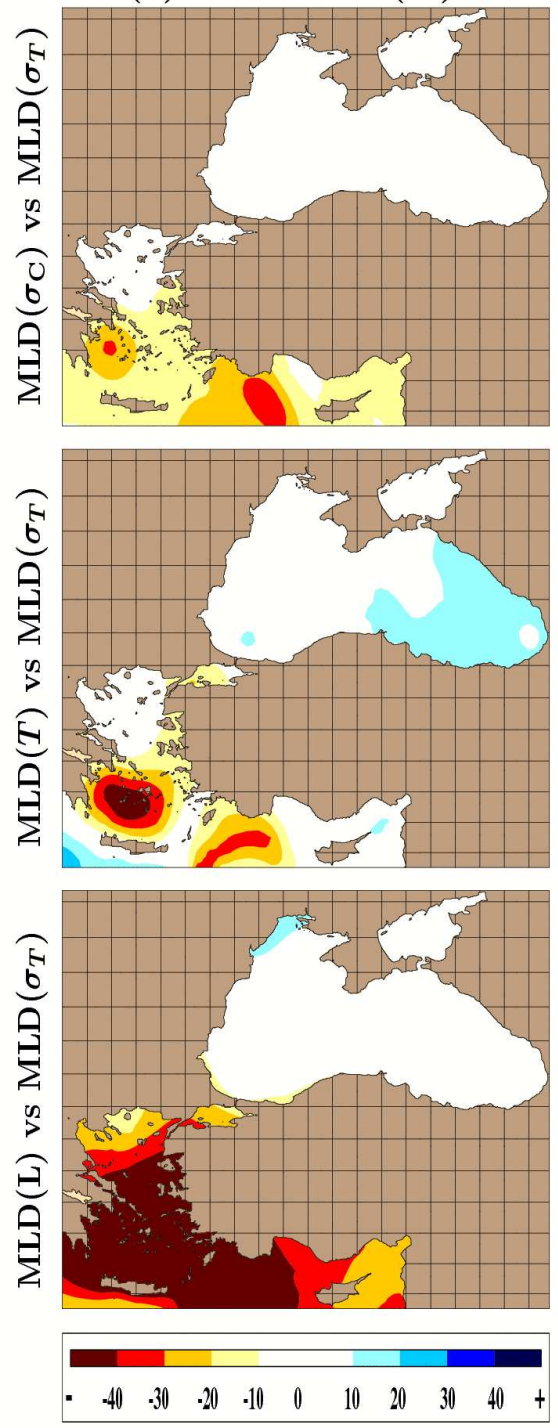

(b) Correlation
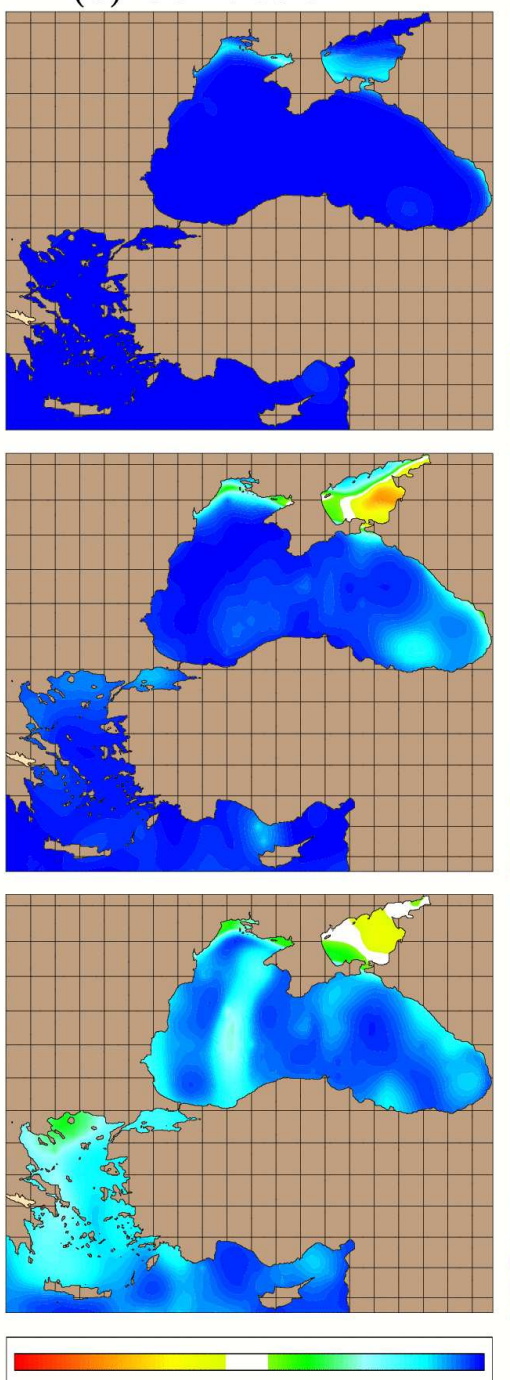

(c) Skill score
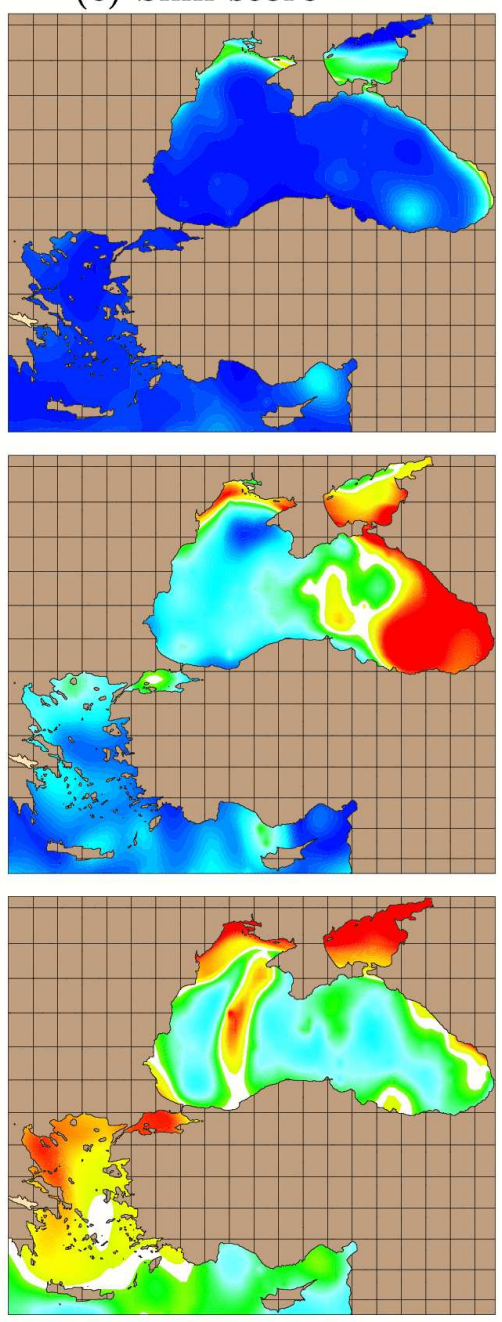

$\begin{array}{lllllllllll}- & -0.8 & -0.6 & -0.4 & -0.2 & 0.0 & 0.2 & 0.4 & 0.6 & 0.8 & 1.0\end{array}$

Fig. 11. Statistical evaluations between the pairs of $\operatorname{MLD}\left(\sigma_{T}\right)$ versus $\operatorname{MLD}\left(\sigma_{C}\right), \operatorname{MLD}\left(\sigma_{T}\right)$ versus $\operatorname{MLD}(T)$ and $\operatorname{MLD}\left(\sigma_{T}\right)$ versus $\operatorname{MLD}(\mathrm{L})$ over the seasonal cycle: (a) Climatological annual mean bias in meters, (b) linear correlation coefficient and (c) non-dimensional skill score. Statistical values were computed using monthly mean time series at each grid point over the seasonal cycle.

purpose is to make the distribution of deviations more symmetric about the mean since the distribution is positively skewed (long tail for larger values), i.e., deep MLDs during winter.

The perfect skill value of 1 is evident between $\operatorname{MLD}\left(\sigma_{T}\right)$ versus $\operatorname{MLD}\left(\sigma_{C}\right)$ almost everywhere (Figure 11c). This indicates that the use of constant density criterion as opposed to the variable one yields almost identical results in this particular ocean domain. However, this is not the case for the pair of $\operatorname{MLD}\left(\sigma_{T}\right)$ versus $\operatorname{MLD}(T)$ in the easternmost part of the Black Sea and some parts of the Azov Sea. The $\operatorname{MLD}(\mathrm{L})$ criterion also gives results very close to the $\operatorname{MLD}\left(\sigma_{T}\right)$ criterion over majority of the domain since positive skill is the criterion for a minimal level of acceptable agreement. However, there are also negative skill values. These are evident in the northeastern Aegean Sea, all Azov Sea and a few small locations in the western Black Sea. 


\section{Summary and Conclusions}

The major focus of this paper is to present climatological monthly mean fields of MLD in the Aegean, Marmara, Black and Azov Seas. Temperature and salinity profiles compiled from various data sets are used to produce relatively fine resolution $\left(0.25^{\circ} \times 0.25^{\circ}\right)$ MLD values. Comprehensive quality control procedures are applied to invidual profiles before forming the monthly climatologies. Various definitions, based on temperature-only, density, and a curvature method; were used to determine MLD. The resulting fields were also compared to each other to determine robustness of the results.

Overall, all definitions reveal the existence of deep (>200 m) mixed layers in the Aegean Sea during winter. On the contrary, much shallower MLDs $(<60 \mathrm{~m})$ are noted in the Black Sea. MLD does not change significantly during summer in both regions. In general, while we have noted a few differences between the results of various MLD definitions over the whole region, the annual cycle remains typically same. Not much seasonal variability is seen in MLD over the Marmara and Azov Seas where there are not many $T$ and $S$ profiles, greatly limiting our ability to obtain reliable fields in some months. Thus, more accurate determination of seasonal MLD variability in these regions are subject to future studies. In particular, the Azov Sea is not an ideal region for mixed layer studies since it is very shallow, and generally $<20 \mathrm{~m}$ in depth. It should be noted that in summer the Azov Sea is strongly stratified due to insolation which has a strong effect due to very low transparency of its water and river discharges. Thus, the mixed layer may hit the bottom.

In this paper, we do not make any concluding remarks about which method of estimation of MLD is better and when a particular one should be used. This requires long term time series of temperature and salinity at some particular locations. However, it is demonstrated that the threshold computation, which is based on a bulk estimation, can result in quite different MLDs in the Aegean Sea in comparison to the curvature methodology. The latter typically returns the shallowest measurable MLD. Additionally, our results reveal that both methodologies generally provide similar information regarding the spatial and temporal variability of MLD and that both fail under certain circumstances. For example, the curvature methodology fails when the water column is well mixed down to the bottom of the profile. In this case, the methodology cannot find a curvature peak, thereby returning a mixed layer value at the shallowest possible point. Similarly the threshold methodology fails when there is a weak shallow stratification with temperature or density deviations smaller than the selected threshold. Evaluations that use both methodologies provide a more robust characterization of the ocean.

\section{Acknowledgments}

This work is supported by the Office of Naval Research (ONR) under The 6.2 project, HYbrid Coordinate Ocean Model and Advanced Data Assimilation. We would like to thank A. Wallcraft and C. Barron for their helpful discussions. Appreciation is extended to reviewers for their comments. This paper is contribution NRL/JA/7320/07/8046 and has been 
approved for public release.

\section{Appendix}

Interpolation of the irregular MLD values to $0.25^{\circ} \times 0.25^{\circ}$ grid are performed using a kriging methodology. The kriging takes into account the presence of noise and constructs a linear predictor based on the covariance structure of the data. The software used for the kriging is the statistical software R (http://www.r-project.org/) with the geostatistical data analysis package geoR (http://www.leg.ufpr.br/geoR). Details about the package can be found in Diggle and Ribeiro (2007).

The kriging parameters that control the linear predictor and the amount of smoothing applied to the output field are the range, sill and nugget. The predictor model is spherical with the parameters and computed by:

(1) the range value of $\phi=2.5^{\circ}$,

(2) the sill value for nugget $=0, \sigma^{\prime 2}=\max \left(4.97 \sigma_{b}-84.3,10\right)$,

(3) nugget $=1.4{\sigma_{o}^{\prime}}^{2} / \phi$, and

(4) ${\sigma^{\prime}}^{2}={\sigma_{o}^{\prime}}^{2}$ - nugget.

The zero nugget sill value of ${\sigma^{\prime}}^{2}$ is computed from the bi-weight standard deviation using empirical parameters (4.97 and -84.3) derived from a linear fit with the sill value computed from a likelihood fit of a spherical predictor model of the variogram. Fitting the bi-weight standard deviation through the empirical parameters is done because the bi-weight standard deviation is a more robust quantity than the variogram. For months with few data the variogram can have unrealistic values while the bi-weight standard deviation remains reasonable.

The kriging field is further smoothed because of (3) above and the limit on how small the sill can be (2). The range value is based on the characteristic length scale derived empirically from variogram computations. It has units of degrees. Based on a likelihood fit of a spherical predictor model to the observational data, the mean value of the sill was $2.5^{\circ}$. The factor of $1.4 \mathrm{in}(3)$ is chosen to represent a characteristic smoothing factor of approximately $1.4^{\circ}$. This is because $\sigma_{o}^{\prime 2} / \phi=\sigma_{o}^{\prime 2} / 2.5=$ nugget/1.4, and the fact that 2.5 is the characteristic factor based on the variogram.

Kriging, as we are using it, assumes that all data values have the same error level. We are not aware of a kriging procedure that would allow for an error specification for each data point. Specifying the error level for each data point could help weight some points less than others and thereby even out data errors and inhomogeneous sampling. For this end, an inverse solver method is being developed that takes into acount variable error levels. The difficulty is in specifying the error. It may be that specifying the error is not realistic and will not help. One of our other future goals is to use co-kriging methodology. With that, we could use different combinations of $\operatorname{MLD}\left(\sigma_{T}\right), \operatorname{MLD}\left(\sigma_{C}\right), \operatorname{MLD}(T)$ and $\operatorname{MLD}(\mathrm{L})$ to get a more robust MLD fields. One could also use the temperature-only estimates to supplement the $T$ and $S$ estimates, so that the gaps where there are no $S$ profiles can be filled. 


\section{References}

Aijun, P., Xiaofang, W., Jindian, X., Xiaogang, G., Li, L., 2006. Barrier layer in the northeastern South China Sea and its formation mechanism. Chinese Sci. Bull. 51, 472-479.

Besiktepe, S., Sur, H. I., Ozsoy, E., Latif, M. A., Oguz, T., Unluata, U., 1994. The circulation and hydrography of the Marmara Sea. Prog. Oceanogr. 34, 285-334.

Boyer, T.P., Antonov, J.I., Garcia, H.E., Johnson, D.R., Locarnini, R.A., Mishonov, A.V., Pitcher, M.T., Baranova, O.K., Smolyar, I.V., 2006. World Ocean Database 2005, DVDs, S. Levitus, Ed., NOAA Atlas NESDIS 60, 190 pp., U.S. Goverment Printing Office, Washington, D.C., USA.

Diggle, P.J., Ribeiro, P.J., Jr, 2007. Model-Based Geostatistics, Springer Series in Statistics. $230 \mathrm{pp}$.

Gould, J., Roemmich, D., Wijffels, S., Freeland, H., Ignaszewsky, M., Jainping, X., Pouliquen, S., Desaubies, Y., Send, U., Radhakrishanan, K., Takeuchi, K., Kim, K., Danchenkov, M., Sutton, P., King, B., Owens, B., Riser, S., 2004. ARGO Profiling Floats Bring New Era of In Situ Ocean Oservation. EOS 85 179, 190-191.

D’Ortenzio, F., Iudicone, D., de Boyer Montegut, C., Testor, P., Antoine, D., Marullo, S., Santoleri, R., Madec, G., 2005. Seasonal variability of the mixed layer depth in the Mediterranean Sea as derived from in situ profiles. Geophys. Res. Lett. 32, L12605, doi:10.1029/2005GL022463.

Helber, R.W., Barron, C.N., Carnes, M.R., Zingarelli, R.A., 2008. Evaluating the sonic layer depth relative to the mixed layer depth. J. Geophys. Res., doi:10.1029/2007JC004595, in press.

Kara, A.B., Rochford, P.A., Hurlburt, H.E., 2000. An optimal definition for ocean mixed layer depth. J. Geophys. Res. 105, 16,803-16,821.

Kara, A.B., Rochford, P.A., Hurlburt, H.E., 2003. Mixed layer depth variability over the global ocean. J. Geophys. Res. 108, 3079, doi:10.1029/2000JC000736.

Kara, A.B., Wallcraft, A.J. and Hurlburt, H.E., 2005. How does solar attenuation depth affect the ocean mixed layer? Water turbidity and atmospheric forcing impacts on the simulation of seasonal mixed layer variability in the turbid Black Sea. J. Climate, 18:389409.

Kara, A.B., Wallcraft, A.J., Hurlburt, H.E., Stanev, E.V., 2008. Air-sea fluxes and river discharges in the Black Sea with a focus on the Danube and Bosphorus. J. Mar. Syst., doi:10.1016/j.jmarsys.2007.11.010.

Lanzante, J.R., 1996. Resistant, robust and non-parametric techniques for the analysis of climate data: theory and examples, incluiding applications to historical radiosonde station 
data. Int. J. Clim. 16, 1197-1226.

Lorbacher, K., Dommenget, D., Niiler, P.P., Kddotohl, A., 2006. Ocean mixed layer depth: A subsurface proxy of ocean-atmosphere variability. J. Geophys. Res. 111, doi:10.1029/2003JC002157.

Lukas, R., Lindstrom, E., 1991. The mixed layer of the western equatorial Pacific Ocean. J. Geophys. Res. 96, 3343-3358.

Millero, F.J., Poisson, A., 1981. International one-atmosphere equation of state of seawater. Deep Sea Res. 28, 625-629.

Miura, T., Suga, T., Hanawa, K., 2002. Winter mixed layer and formation of dichothermal water in the Bering Sea. J. Oceanography 58, 815-823.

Murphy, A.H., 1995. The coefficients of correlation and determination as measures of performance in forecast verification. Wea. Forecasting 10, 681-688.

Ohno, Y., Kobayashi, T., Iwasaka, N., Suga, T., 2006. The mixed layer depth in the North Pacific as detected by the Argo floats. Geophys. Res. Lett. 31, L11306, doi:10.1029/2004GL019576.

Oguz, T., Ducklow, H.W., Malanotte-Rizzoli, P., 2000. Modeling distinct vertical biogeochemical structure of the Black Sea: Dynamical coupling of the oxic, suboxic, and anoxic layer. Global Biogeochem. Cycles 14, 1331-1352.

Oguz, T., Malanotte-Rizzoli, P., Ducklow, H.W., 2001. Simulations of phytoplankton seasonal cycle with multi-level and multi-layer physical-ecosystem models: the Black Sea example. Ecol. Model. 44, 295-314.

Ribeiro, P.J. Jr., Diggle, P.J., 2007. Bayesian interence in Gaussian model-based geostatistics. Techn. Report, ST-99-08, Department of Mathematics Statistics, Lancaster University, LA1 4 YF Lancaster, UK.

Sprintall, J., Tomczak, M., 1992. Evidence of the barrier layer in the surface layer of tropics. J. Geophys. Res. 97, 7305-7316.

Suga, T., Motoki, K., Aoki, Y., Macdonald, A.M., 2004. The North Pacific climatology of winter mixed layer and mode waters. J. Phys. Oceanogr. 34, 3-22.

Qu, T., Du, Y., Gan, J., Wang, D., 2007. Mean seasonal cycle of isothermal depth in the South China Sea. J. Geophys. Res. 112, C02020, doi:10.1029/2006JC003583.

Teague, W.J., Carron, M.J., Hogan, P.J., 1990. A comparison between the Generalized Digital Environmental Model and Levitus climatologies. J. Geophys. Res. 95, 7167-7183.

Wilks, D. S., 1995. Statistical Methods in the Atmospheric Sciences. Academic Press, San Diego, 467 pp. 